\title{
Role of Moves, Tenses, and Metadiscourse in the Abstract of an Acceptable Research Article
}

\author{
Yasir Bdaiwi Jasim Al-Shujairi \\ Faculty of Modern Language and Communication, University Putra Malaysia, 43400 Serdang, Selangor, Malaysia \\ Email: yasir.bdaiwi.jasim1990@gmail.com \\ Mohammed Sani Ya'u \\ Faculty of Languages and Education, Bauchi State University, Gadau, P.M.B. 65, Gadau, Bauchi State, Nigeria \\ Email: elmuhsan@gmail.com

\section{Jamila AbdulAzeez Buba} \\ Faculty of Modern Language and Communication, University Putra Malaysia, 43400 Serdang, Selangor, Malaysia \\ Email: Jamila_abdulazeez@yahoo.com
}

Doi:10.5901/mjss.2016.v7n2s1p379

\section{Abstract}

The first part the reviewers of journals article read in any research is its abstract. It tells the summary of the research and defines the language used by the researcher. Thus, well-written abstract is necessary for all academic writers who consider publishing their papers. Certainly, writers could find it difficult to write abstract if they are not very familiar with the moves and the linguistic features associated with it. Therefore, this study aims to explore the rhetorical moves in the abstracts of 59 published research articles selected from two disciplines specified in English. Furthermore, it examines the verb tense and the metadiscourse features in each move. All Research Articles (RAs) were published in Pertanika Journal of Social Sciences \& Humanities from 2011 until 2015. Two models proposed by Hyland in (2000) and (2005) were used as analytical frameworks in the present study. The findings showed that some rhetorical moves seemed to have higher occurrences than the others. Regarding the verb tense, present tense was found to be more preferable tense in the process of writing abstract. Moreover, interactive metadiscourse features appeared more frequently than interactional features.

Keywords: abstract, moves, metadiscourse, tenses

\section{Introduction}

Recently, Research articles (RA hereafter) abstract started to play an important role in academic community. As a genre in academic context, Hyland (2000) stated that RA abstract functions as an "advertising means" to bring the attention of reader to the whole research paper. Not to mention, there are certain moves in the abstract which present the flow of the discourse need to be indicated. Through abstract, reader can expect the quality of the research and decide whether the article is worth the reading or not (Martin-Martin, 2003). Similarly, Journal article reviewers are readers as well but professional readers who read any paper extensively and review it critically. The publication of any paper is relies on their judgment. The first part they read in research is its abstract, the rhetorical pattern found and the language used in the abstract are two main aspects they put into consideration. Thus, the writer should be careful in the way they write the abstract and the appropriate linguistics features need to be used.

Abstract involves metadiscourse which associates the appropriate use of linguistic realization. In addition, the select of verb tense in the process of writing an abstract should be systematic and not random. In other words, there are certain tenses could be use in writing abstract and the way we apply two different tenses must be compatible with the content. Therefore, the two aspects like tense and metadiscourse are very important in any RA abstract.

One important linguistic realization used in the abstract is tenses. The use of tenses in the abstract varies according to the writer and the topic. Furthermore, it could vary from one move to another within the same text. The shift in tenses that could be observed in RA abstract is of great importance and need to be clearly understood by the writers. According to Santos (1996), simple present and present perfect have been found to be the dominant tenses in move 1 
(the introduction) as the researchers tended to apply these present tenses to state general background about the topic. In addition, he found that simple past, simple present modals signaled move 3 (the purpose). Regarding move 3, Santos observed that whenever the sentence started with the subject (this paper) or (this article), simple present tense was used and whenever the sentence started with (the research) or (the study), simple past tense was used. In this line, Malcolm (1987) argued that the research article is a "communicative event" contains two different times. The first is the moment of reading and the second is the moment of writing.

Regarding the metadiscourse, Zellig Harris (1959) coined the term metadiscourse. It represents what the sender attempts to guide the receiver's perception of a text. Later on, Hyland (2005) defined metadiscourse as an umbrella term to include an apparently heterogeneous array of cohesive and interpersonal features which help relate a text to its context. He sub-categorized the features of metadiscourse into two main categories: interactive and interactional. The former helps the reader to move through the test as a whole while the later takes the reader involvement further step deeper. Unlike L1 writers, L2 writers learn the functions of the metadiscourse features consciously by instruction form. The use of metadiscourse features shows the writer's "friendly" attitude to the reader and provides coherent and related ideas from one to another (Hyland, 2005).

Therefore, along with the rhetorical moves, the two linguistic realizations that have been mentioned above are very significant for writing abstract. Journal reviewers might base their judgments about the research on the abstract part. Thus, academic writers who consider publishing their research paper in a high impact factor journal need to be aware of the rhetorical moves found in the abstract. More significantly, they need to understand the linguistics' features in each move and apply them when they write an abstract.

\subsection{Research Questions}

The present study aims to answer the following questions:

1- What are the common rhetorical moves in published RA abstracts?

2- What are the preferred tenses applied in each move in the abstract?

3- What are the metadiscourse features used in the abstract's moves?

\section{Literature Review}

In fact, abstract is one of the most important parts in any research article. "The abstract is generally the readers' first encounter with a text, and is often the point at which they decide whether to continue and give the accompanying article further attention or to ignore it" Hyland (2000). According to Bhatia (1993), an abstract is "a description or factual summary of the much longer report, and is meant to give the reader an exact and concise knowledge of the full article". Thus, studies on writing RAs abstracts in particular are of high significant for the academic writers.

In the past few years, studies on the rhetorical pattern in the abstracts have been received an intention among scholars. For example, Doro, k., (2013) analyzed the rhetorical moves in two fields of English namely; linguistics and English literature. The findings showed that all the five moves are included in only 5 abstracts. In addition, it was found that move2 (presenting the research) and move3 (methodology) are the most frequently employed moves. Regarding to the differences, the result showed that linguistics abstracts seem to follow the five moves more than the literature abstracts. In another study, Suntara \& Usaha (2013) examined the rhetorical patterns in 200 abstracts of two disciplines; linguistics and applied linguistics. All the selected abstracts are published between 2009 and 2012. The findings showed three conventional moves in both disciplines namely; the purpose move, the method move and the findings move. In contrast, the introduction move and the conclusion move were found to be optional. In the same vein, (Samraj, 2005; Pho, 2008; Cross and Oppenheim, 2006; Ren \& Li 2011) are all studies which investigated the rhetorical pattern in abstract writing. However, only few studies have been conducted to investigate the linguistics realizations that accompany the moves in the abstract.

One of the linguistic realizations in abstract writing is verb tense. Salager- Meyer (1992), for example, analyzed the abstracts written in medicine across various genres. This researcher found some interesting results. He discovered that simple past tense and simple present tense are mainly used in medical abstracts for very different purposes. In another study, Tseng (2011) examined 90 research article abstracts in three applied linguistics journals. He found fourmoves structure, and the dominant tense used was simple present tense. He attributed the dominance of present tense to the nature sub-disciplines in applied linguistics. More recently, Esfandiari (2014) conducted a study that examined the use of rhetorical moves and verb tense in two sub-disciplines of computer science. In terms of verb tense, Esfandiari (2014) found that present tense is the preferred tense in both sub-disciplines. 
Another important linguistic realization in writing abstracts is the use of metadiscourse features. Limited studies have examined the metadiscourse features that accompany the moves in the abstract. Lon et al., (2012) for example, analyzed the move pattern along with the metadiscourse features. 100 abstracts of undergraduates' final term papers from Computer and Communication System Engineering have been selected to be investigated. Santos' (1996) model of five moves and Hyland (2005) model of metadiscourse features have been adopted as frameworks of analysis. The findings showed that not all moves are used in sequence from Move 1 to Move 5, while the omission of move 4 (the findings) and 5 (the conclusion) have been occurred in most of their abstracts. Moreover, it has been found that students have limited capacity in the use of metadiscourse features in their writing abstract. The study suggested that teachers and students need to be explicitly aware of the five moves and the metadiscourse discourse features that accompany them. In the same line, Khedri et al (2015) investigated Interpersonal-driven Features in Research Article Abstracts in two disciplines namely; applied linguistics and Economics. The findings showed that there is a variation across the two fields of knowledge studied.

In short, recently, the stress of the studies on RA abstracts proves the importance of a well-written abstract in the academic community. According to Lores (2004), abstracts "constitute the gateway that lead readers to take up an article, journals to select contributions, or organizers of conferences to accept or reject papers". However, many writers are not aware of the moves and the linguistic realizations that construct an acceptable abstract. Therefore, they face difficulties in publishing their research articles in a high impact journal. Accordingly, the present study seeks to shed light on the components that construct a well written abstract.

\section{Method}

\subsection{The Corpus Selected}

The corpus of this study is $60 \mathrm{RA}$ abstracts. They have been selected from two disciplines, which are applied linguistics (AL) and teaching English as a second language (TESL). The reason behind selecting RA from these two disciplines is because the authors of such studies are specialized in English and more experts in the use of language than those who are from different fields. All articles that have been selected were taken from Pertanika journal of social science and humanities (official journal of University Putra Malaysia that is scopus indexed journal and considered to be a high impact factor journal. In addition, all articles have been published very recently, between 2011 and 2015.

\subsection{The Models of Analysis}

Santos' (1996) and Hyland's (2000) are two significant models in abstract writing that have been repeatedly mentioned and used in the literature. Similarly, both models have five moves and their functions are almost the same. Santos' (1996) model was based on the abstract in the field of applied linguistics while Hyland's (2000) model was based on various disciplines such as; applied linguistics, marketing, engineering, physics and etc. To answer the first question, Hyland's (2000) model is more suitable for the purpose of this study that seeks to help the academic writers in all fields of knowledge about the components that create a well-written abstract.

Figure 1: Santos's (1996) five moves model

\begin{tabular}{|l|l|}
\hline Move & Move \\
\hline Move 1: Situating the research & Setting the scene for the current research (topic generalization) \\
\hline Move 2: Presenting the research & Stating the purpose of the study, research questions and/or hypotheses \\
\hline Move 3: Describing the methodology & Describing the materials, subjects, variables, procedures \\
\hline Move 4: Summarizing the findings & Reporting the main findings of the study \\
\hline Move 5: Discussing the research & Interpreting the results/findings and/or giving recommendations, implications/applications of study \\
\hline
\end{tabular}

To indicate whether a particular move was obligatory or optional, the frequency of each move was counted. According to Santos's (1996) results, $80 \%$ was established as the benchmark for an obligatory move. The move was considered an optional when the frequency of its occurrence in all abstracts is below $80 \%$.

The present study also seeks to analyze the tenses and identify the preferred tense used in each move in the abstract. The verb tense used in each move has been identified manually by reading the abstract and looking at each move. 
Regarding the metadiscourse features, Hyland's model (2005) of interpersonal metadiscourse taxonomy has been adopted to analyze and identify the features of metadiscourse used in each move in RA abstracts. First, the metadiscourse features have been manually recognized according to the sub categories in Hyland's model. Then, the recognized words were searched using AntConc program to identify the frequency of their occurrence in the text.

Figure 2. Hyland's Metadiscourse Model (2005)

\begin{tabular}{|l|l|l|}
\hline Category & Function & Examples \\
\hline Interactive & Help to guide the reader through the text & Resources \\
\hline Transition & Express relations between clauses & Moreover;; however; therefore; and \\
\hline Frame markers & Refer to discourse acts, sequences or stages & Firstly; in conclusion; purpose \\
\hline Endophoric markers & Refer to information in other parts of the text & In this part; In Chapters 2; in section 1 \\
\hline Evidentials & Refer to information in other texts & According to z; cite \\
\hline Code glosses & Elaborate propositional meanings & Specifically; for example; defined as \\
\hline Interactional & Involve the reader in the text & Resources \\
\hline Hedges & Withhold commitment and open dialogue & Claim; may; sometimes \\
\hline Boosters & Emphasize certainty or close dialogue & In fact; indeed; show \\
\hline Attitude markers & $\begin{array}{l}\text { Express writer's attitude } \\
\text { toward the propositional information }\end{array}$ & $\begin{array}{l}\text { Important; I agree; } \\
\text { Prefer }\end{array}$ \\
\hline Self-mentions & Explicit reference to the writer & ;; we; my; the author; us \\
\hline Engagement markers & Explicitly build relationship with reader & Classify; increase; state \\
\hline
\end{tabular}

\section{The Findings}

\subsection{Moves}

Table 1: The rhetorical moves in RA abstracts

\begin{tabular}{|l|c|c|c|c|c|}
\hline Moves & $\mathbf{1}$ & $\mathbf{2}$ & $\mathbf{3}$ & $\mathbf{4}$ & $\mathbf{5}$ \\
\hline Total number of Occurrence & 34 & 55 & 56 & 48 & 33 \\
\hline Percentage (\%) & $57.6 \%$ & $93.2 \%$ & $94.9 \%$ & $81.3 \%$ & $55.9 \%$ \\
\hline
\end{tabular}

Table 1, shows that the most frequent move used is move 3 (describing the methodology) which has $94.9 \%$, followed by move 2 (presenting the research) which has 93.2\%, and move 4 (summarizing the findings) with $81.3 \%$, and the data analysis shows that the less frequent move used is discussing the research which has $55.9 \%$.

\subsection{Tenses}

Table 2: The frequency and the percentage of the tense used

\begin{tabular}{|l|c|c|c|c|c|c|c|}
\hline Moves & Move 1 & Move 2 & Move3 & Move 4 & Move5 & Total number & Percentage \\
\hline Present & 34 & 34 & 15 & 19 & 26 & 128 & $56.7 \%$ \\
\hline Past & 0 & 21 & 41 & 29 & 6 & 97 & $42.9 \%$ \\
\hline Future & 0 & 0 & 0 & 0 & 1 & 1 & $0.4 \%$ \\
\hline
\end{tabular}

Table 2 indicates that the most frequent used tense in the moves is the present tense which has $56 \%$, followed by past tense with a percentage of $42.9 \%$, and the least frequent used tense is the future tense, which has 0.45

\subsection{Metadiscourse Features}

Table 3: Top six linguistics realizations

\begin{tabular}{|c|c|c|c|c|c|}
\hline And & Also & This study & The study & Focus & Indicate \\
\hline 373 & 28 & 45 & 36 & 20 & 19 \\
\hline
\end{tabular}


Moving to metadiscourse, the 6 most common linguistic realizations are And, Also, This study, The study, Focus, and Indicate. However the realization that occurs most frequently is And which appeared 373 times in the research abstracts; and the least realization is indicate which appeared only 19 times. It is important to note that the authors of this study found out that The study and This study also have high frequency of usage, even though they are not included in Hylands 2005 model of metadiscourse features.

\subsubsection{Interactive Metadiscourse}

Table 4: Transitions

\begin{tabular}{|c|c|c|c|c|c|c|}
\hline And & Also & While & But & In addition & However & Thus \\
\hline 373 & 28 & 11 & 11 & 11 & 9 & 6 \\
\hline
\end{tabular}

In interactive metadiscourse the transition markers (see table 7 above) that are found are And, Also, While, But, In addition, However, Thus. The word that occur most frequently is And, while the least is Thus

Table 5: Frame markers

\begin{tabular}{|c|c|c|c|c|c|c|}
\hline Focus & Aim & Well & Purpose & Then & After & Before \\
\hline 20 & 16 & 13 & 9 & 8 & 7 & 6 \\
\hline
\end{tabular}

As for the frame markers, (focus, aim, well, purpose, then, after, before) are commonly used. But the most frequently used among them is (focus) which has the highest frequency while (before) has the least frequency of occurrence.

Table 6: Elaborators

\begin{tabular}{|c|c|c|c|}
\hline Namely & Such as & Specifically & That is \\
\hline 8 & 7 & 3 & 3 \\
\hline
\end{tabular}

The above table shows that Namely as an elaborator has the highest occurrence, then followed by such as, which occurred 7 times while specifically and that is has the least with 3 occurrences each.

\subsubsection{Interactional Metadiscourse}

Table 7: Hedges

\begin{tabular}{|c|c|c|c|c|c|c|c|}
\hline Indicate & About, & Should, & May & Could & Mainly, & Argue, & Frequently \\
\hline 19 & 12 & 10 & 9 & 8 & 5 & 5 & 3 \\
\hline
\end{tabular}

In interactional metadiscourse, the hedging device that appeared most frequently is Indicate (19) followed by About (12), while frequently has the least usage in the hedging category.

Table 8: Boosters

\begin{tabular}{|c|c|c|c|c|c|c|c|}
\hline Find & Found & Show & Showed & Indicate & Indicated & Have & Has \\
\hline 3 & 13 & 10 & 16 & 9 & 7 & 29 & 13 \\
\hline
\end{tabular}

The boosters that are commonly found in the corpus of this study are Find, Found, Show, Showed, Indicate, Indicated, Have, and Has. The most frequently used is Have with 29 occurrences while the least used is Find with 3 occurrences (see table 11 above)

Table 9: Attitude Markers

\begin{tabular}{|c|c|c|c|c|c|}
\hline Important & Expected & Essential & Interesting & Correctly & Even \\
\hline 7 & 3 & 2 & 2 & 1 & 2 \\
\hline
\end{tabular}


In terms of occurrence in attitude markers, the expression Important has the highest number of occurrence with (7) occurrences, followed by Expected with (3) and Essential, Interesting and Even has (2) respectively. The least attitude marker that is used is Correctly with only a single appearance.

Table 10: Self mentions

\begin{tabular}{|c|c|c|c|c|c|}
\hline We & Our & My & I & The author & The writer \\
\hline 3 & 3 & 1 & 2 & 1 & 1 \\
\hline
\end{tabular}

The preferred form of self-mention is the personal pronoun We and Our, against the possessive case of My, The author, and The Writer.

Table 11: Engagement Markers

\begin{tabular}{|c|c|c|c|c|c|c|}
\hline Selected & Determine & Increase & Analyzed & Observed & Have to & Consider \\
\hline 9 & 7 & 3 & 3 & 4 & 3 & 3 \\
\hline
\end{tabular}

The engagement markers that were identified (see table 14 above), among them, the most frequently used marker is Select, which appeared 9 times, followed by Determined with 7 occurrences, Observed had 4, while Increase, Analyzed, Have to and consider have 3 occurrences each.

\section{Discussions and Conclusion}

In view of the frequency analysis of abstracts from the corpus, it could be concluded that some rhetorical moves appeared to have higher incidence of occurrences than the others. This disparity in the occurrences might be connected to the obligatory and optionality of the moves in the abstracts. Accordingly, the data obtained from the corpus of this study reveal that move 2, 3, and 4 emerged to have higher percentages of the occurrences (see table 3 ) of which according to the Santos' (1993) benchmark are considered obligatory rhetorical moves. That means, they all have 80 percentages and above. Contrariwise, move 1 and 5 are considerably optional moves for their lower entries in the abstracts. Considering the fact that move 1 has a high incidence of occurrence in the corpus, it does not qualify to be obligatory in accordance with the benchmark. It appears that writers of these abstracts seem to prefer a direct approach while writing abstracts, owing to their ultimate goals which are reflected in the introductory line, avails the reader an overview on what study is all about. Therefore, the finding demonstrates that move 3 which describes the methodology, has the highest frequency of occurrence as it represents $94.9 \%$. The antecedence of methodology has characterized with detailed explanation of procedures used in data collection. This move is followed by 2, that is, presenting the research which has $93.2 \%$ (see table 3). However, considering the fact that move 1 has a high incidence of occurrence in the corpus, it is not qualified to be obligatory move in accordance with the said benchmark. It gives the impression that writers of these abstracts seem to prefer a direct approach while writing, owing to the fact that their ultimate goals are reflected in the introductory line which avails the reader an overview on what the paper is all about. Obviously, it is really interesting as the finding indicates that move 2, 3 and 4 are found to be conventional since they showed greater frequencies compared to move 1 and 5 . These results seem to coincide with Santos' (1996) results in virtually all respects. It differ with Santos' only in the number of percentages, but the conventionality (obligatory) and optionality of the moves remain the same. This is presumably because writers mainly focused on purpose of the study, methodology applied as well as findings derived from the study which they considered it to be most important sections in the abstracts. However, move 5 emerges the least amongst the five moves examined as it has the lowest tokens. Considerably, this is not unconnected to the attitude of writers, thinking that since all the information needed have already been stated in the abstract, it is not necessary to restate it in the conclusion move. The writers therefore tend to ignore this move, sometimes deliberately. In essence, to buttress this claim, there is a study conducted by San et al (2012) who found, in their comparative study of rhetorical moves in abstracts, that conclusion has the least tokens with only $20 \%$ in the abstracts of expert writers. Above all, this can be supported by number of previous studies in the field of genre studies. For example, Lon et al (2012) and Doro (2013) found second, third and fourth move preference patterns in the abstracts studied. Although they used Hyland's (2000) model of rhetorical move analysis, Espandiari (2014) and Suntura \& Usaha (2013) revealed a consistent finding.

With reference to the occurrence of tense type, it is obvious that finding indicates that present tense is the most prevalent tense in the corpus. Being dominant tense used in the abstracts, it is not far away from the fact that writers use 
it to show the current state of knowledge. Hence, present tense may be preferred tense for that matter. However, this finding is backed up by the findings of various studies such as Tseng (2011), Saboori \& Hashemi (2013) and Espandiari (2014) whom in their studies that concern with the analysis of verb tense respectively found results that are in congruent with this study. In the contrary, Swales \& Feak (2004) who also examined verb tense found results that contradict this study as he discovered that researchers often use present tense in the opening and concluding sentences of their abstracts.

The point that should not be overlooked here is the metadiscoursal elements used by the writers of the abstracts. Apparently, the study reveals an interesting finding as the interactive instances appeared most frequently thereby indicating that writers bear their readers in mind while writing an academic work. For all intents and purposes, writers organise the discourse in such a way that their intents will easily be deduced by their readers due to the way they manage the flow of information. This can be seen from data pictured in the tables above. For instance, the use of transitions, frame markers etc which exhibited highest tokens are the testimony of cohesive discourse organisation. However, various instances of interactional metadiscourse found in the corpus showed writers' approaches to interact with readers by proposing their arguments, their feelings, their attitudes and above all their commitment to the texts itself. Thus, writers clearly share their ideas with a view to involve their readers into the discourse. This is justifiable as the study indicates frequent use of hedges and boosters by abstract writers. Most importantly, through the interactional metadiscourse elements, writers distinguish between facts and opinions in academic writings. Also, the propositions of writers appeared to be sound and indeed persuasive to their readers. Essentially, this study will perhaps guide the readers to detect the rhetorical moves present in the writers' abstracts and to past value judgement on whether the available moves in the abstracts are in accordance with a certain model. It prepares the readers with the knowledge of the types of rhetorical moves that are expected to be present in an acceptable abstract. This study may also help the readers to know the appropriate tenses to be used in writing (reporting the moves) the abstract and exposes them with the knowledge of metadiscourse elements that are suitable according to the contextual situation in the written abstracts examined in this study. This study would probably contribute to the field of discourse analysis as it studies not only rhetorical moves analysis but also tenses and metadiscourse features in the abstracts investigated.

\section{References}

Bhatia, V.K. (2006). Analyzing Genre: Some Conceptual Issues. In M. Hewings (Ed.) Academic Writing in Context: Implications and Applications (pp.79-92). Birmingham: University of Birmingham Press.

Cross, C., \& Oppenheim, C. (2006). A genre analysis of scientific abstracts. Journal of documentation, 62(4), 428-446.

Doró, K. (2013). The Rhetoric Structure of Research Article.

Esfandiari, R. Realization of rhetorical moves and verb tense variation in two subdisciplines of computer sciences: Artificial intelligence and architecture.

Hyland, K. (2005). Metadiscourse: Exploring interaction in writing. New York: Continuum.

Hyland, K. (2005). Metadiscourse. John Wiley \& Sons, Inc.

Hyland, K. (2000). Disciplinary Discourses: Social Interactions in Academic Writing. London: Longman.

Harris, Z. S. (1959). Transformations and Discourse Analysis Papers.

Khedri, M., Chan, S. H., \& Helen, T. (2015). Interpersonal-driven Features in Research Article Abstracts: Cross-disciplinary Metadiscoursal Perspective. Pertanika Journal of Social Sciences \& Humanities, 23(2).

Lon, C. E., Tan, H., \& Abdullah, A. N. (2012). Conveying Communicative Intent: Moves and Metadiscourse in Abstract Writing. International Journal of Applied Linguistics and English Literature, 1(7), 56-65.

Lores, R.(2004). On RA abstracts: From rhetorical structure to thematic organization. English for Specific Purposes, 23, $280-302$.

Martín, P. M. (2003). A genre analysis of English and Spanish research paper abstracts in experimental social sciences. English for Specific Purposes, 22(1), 25-43.

Pho, P.D. (2008). Research article in Applied Linguistics and Educational Technology: A study of linguistic realizations of rhetorical structure and authorial stance. Discourse Studies, 10 (2),231-250.

Ren, H., \& Li, Y. (2011). A comparison study on the rhetorical moves of abstracts in published research articles and Master's foreignlanguage theses. English Language Teaching, 4(1), p162.

Saboori, F., Hashemi, M. R., (2013) A cross-disciplinary move analysis of research Article abstracts, International Journal of Language Learning and Applied Linguistics World, vol., 4 (4), 2289-3245.

Salager-Mayer, F. (1991) A text-type and move analysis study of verb tense and modality distribution in medical English abstracts. English for Specific Purposes, 11, 93-113.

Samraj, Betty. (2008). A discourse analysis of master's theses across disciplines with a focus on introduction. Journal of English for Academic Purposes, 7, 55-67.

Samraj, B. (2005). An exploration of a genre set: Research article abstracts and introductions in two disciplines. English for Specific Purposes, 24,141-156. 
Santos, M.B.D. (1996). The textual organization of research paper abstracts in Applied Linguistics. Text, 16, 481-499.

San, L. Y., \& Tan, H. (2012). A comparative study of the rhetorical moves in abstracts of published research articles and students' term papers in the field of computer and communication systems engineering. International Journal of Applied Linguistics and English Literature, 1(7), 40-50.

Suntara, W., \& Usaha, S. (2013). Research article abstracts in two related disciplines: Rhetorical variation between linguistics and applied linguistics. English Language Teaching, 6(2), p84.

Swales, J. M., \& Feak, C. B. (2004). Academic writing for graduate students. (2nd ed.). Ann Arbor: University of Michigan Press.

Talebzadeh, H., Ghafar Samar, R., Kiany, G. R., \& Akbari, R. (2014). Steps to a successful abstract: A comparative genre analysis. The International Journal of Humanities, 20(3), 1-25.

Tseng, F.P. (2011). Analyses of move structure and verb tense of research article abstracts in Applied Linguistics journals. International Journal of English Linguistics, 1(2), 27-39. 